\title{
Comparison of surface electromyographic activity of erector spinae before and after the application of central posteroanterior mobilisation on the lumbar spine
}

\author{
Georgios Krekoukias, Nicola J. Petty, Liz Cheek
}

\begin{abstract}
Lumbar spine accessory movements, used by therapists in the treatment of patients with low back pain, is thought to decrease paravertebral muscular activity; however there is little research to support this suggestion. This study investigated the effects of lumbar spine accessory movements on surface electromyography (sEMG) activity of erector spinae.

A condition randomised, placebo controlled, repeated measures design was used. sEMG measurements were recorded from 36 asymptomatic subjects following a control, placebo and central posteroanterior (PA) mobilisation to L3 each for 2 min. The therapist stood on a force platform while applying the PA mobilisation to quantify the force used. The PA mobilisation applied to each subject had a mean maximum force of $103.3 \mathrm{~N}$, mean amplitude of force oscillation of $41.1 \mathrm{~N}$, and a frequency of $1.2 \mathrm{~Hz}$. Surface electromyographic data were recorded from the musculature adjacent to L3, L5 and T10.

There were statistically significant reductions of 15.5\% (95\% CI: 8.0-22.5\%) and 17.8\% (95\% CI: 12.9-22.4\%) in mean sEMG values following mobilisation compared with the control and placebo, respectively.

This study demonstrates that a central PA mobilisation to L3 results in a statistically significant decrease in the sEMG activity of erector spinae of an asymptomatic population.
\end{abstract}

Keywords: Mobilisation; Erector spinae; Electromyography; EMG

1. Introduction

Patients with low back pain often present with reduced lumbar spine mobility and this may be associated with increased paraspinal muscle activity (Chen et al., 1998; Chiou et al., 1999; Lariviere et al., 2000; Lehman, 2002; Lofland et al., 2000; Mannion et al., 1997). During clinical examination of these patients, therapists' perception of increased lumbar posteroanterior (PA) stiffness (Latimer et al., 1996) may be due to this increase in paraspinal muscle activity (Colloca and Keller, 2001; Lee et al., 1993; Shirley, 2004; Shirley et al., 1999). Therapists may treat PA stiffness by manually applying rhythmical oscillatory forces to the spinous processes of the lumbar spine.

The effect of an oscillatory PA force to the lumbar spinous process has been shown to produce a generalised extension movement (Lee et al., 1994; Lee and Evans, 1997) as far as T8 (Lee and Svensson, 1993). All the neuromusculoskeletal tissues in the region will therefore be affected by the oscillatory force; there will be movement of the interbody and zygapophyseal joints and their accompanying periarticular tissues, as well as local musculature and neural tissues. Because of this, PA mobilisation treatment is 
likely to have widespread effects in a number of tissues. One suggested effect is reduced paraspinal muscle activity (Maitland et al., 2005; Zusman, 1986).

There is support in the literature that oscillatory joint movement influences muscle activity; but it is still unclear in what direction. Some studies have found a reduction in spinal motor excitability in the lower limb (Cheng et al., 1995; Freeman and Wyke, 1967) while in the upper limb one study found an increase in corticomotor activity (Lewis et al., 2001) and one a decrease (Edwards et al., 2002).

While there have been a large number of studies investigating the effect of a spinal manipulative thrust on local muscle activity (for example DeVocht et al., 2005; Dishman and Burke, 2003; Ritvanen et al., 2007), there have been only two studies that have specifically explored the effect of oscillatory joint mobilisation on local muscle activity; one study on the temporomandibular region and the other on the cervical spine (Sterling et al., 2001; Taylor et al., 1994). Both these studies used surface electromyography (sEMG) to measure a change in muscle activity. While there are limitations of sEMG to isolate particular muscles (Basmajian and DeLuca, 1985; DeLuca, 1997; Ferdjallah and Wertsch, 1998; Wolf et al., 1991), it has been demonstrated to accurately record signals from the erector spinae (Stokes et al., 2003; Wolf et al., 1991).

The sEMG activity of the masseter muscle before and after oscillatory grade IV distraction mobilisations over the lower molar teeth was used with 15 subjects with temporomandibular pain and dysfunction (Taylor et al., 1994). The application of the mobilisation lasted for 3 min (three repetitions of 1 min duration with $10 \mathrm{~s}$ intervals). Following mobilisation there was a statistically significant $(p<0.05)$ decrease in resting and clenched masseter sEMG immediately and after $15 \mathrm{~min}$, compared with a placebo treatment.

The effect of cervical spine mobilisation on sEMG of sternocleidomastoid in 30 subjects with chronic ( 3 months or more) mid to lower cervical spine pain was investigated by Sterling et al. (2001). sEMG activity of the superficial neck flexor muscles during the cranio-cervical flexion test was measured before and after an oscillatory Grade III unilateral posteroanterior mobilisation to the articular pillar of $\mathrm{C} 5 / 6$ on the subject's symptomatic side. The mobilisation lasted $3 \mathrm{~min}$ (three repetitions of $1 \mathrm{~min}$ duration, with I minute rest period between the applications of pressure). Following mobilisation, there was a statistically significant $(p<0.0002)$ decrease in sEMG of both left and right neck flexor muscles compared to control or placebo conditions.

To further elucidate the effect of spinal joint mobilisation on muscle activity, this study investigated the effect of lumbar PA mobilisation on paraspinal sEMG of asymptomatic subjects. The lack of information in the literature concerning the effect of central lumbar posteroanterior mobilisation on the surrounding musculature led to the a non-directional experimental hypothesis (Hicks, 1995; Jenkins et al., 1998) that there would be a change in the magnitude of resting sEMG activity in standing before and after the application of central lumbar posteroanterior pressures.

\section{Methods}

A condition randomised, placebo controlled, repeated measures design was used to identify the differences in the magnitude of sEMG activity of the lumbar and thoracic section of the erector spinae musculature of healthy subjects after applying central posteroanterior (PA) mobilisation to L3. The L3 level was selected because of its approximate central position in the lumbar lordosis which suggests that a posteroanteriorly directed force would mainly translate the vertebra anteriorly (Harms and Bader, 1997; Lee et al., 1990). Ethical approval was obtained from the University of Brighton Ethics Committee and all subjects gave informed consent.

\subsection{Subjects}

Thirty-six subjects, 10 male and 26 female aged between 18 and 48 years (mean 26.8 SD 7.1) participated in the study. Subjects were included if they were non-disabled, had a body mass index (BMI) less than $28 \mathrm{~kg} / \mathrm{m}^{2}$ and their age was between 18 and 65 years. The BMI limit was chosen to obtain comparable thickness of subcutaneous tissues between subjects (Lariviere et al., 2000) in order to enhance the accuracy of sEMG amplitude recordings (DeLuca, 1997; Ferdjallah and Wertsch, 1998). The upper age limit was chosen because of the decrease in skin conductivity with age (Hodges and Bui, 1996), which may have interfered with sEMG recordings. Exclusion criteria were history of low back pain within 6 months prior of the study, history of lumbar spine surgery, osteoporosis, rheumatoid arthritis, lower limb neurological signs and spondylolisthesis.

\subsection{Instrumentation, procedure and measurements}

With the subject lying prone on an adjustable plinth the researcher palpated and marked the spinous process of L5, L3 and T10. In an attempt to enhance the reliability and validity of palpation (Binkley et al., 1995; McKenzie and Taylor, 1997; Newton and Waddell, 1991), levels were cross-checked in three different ways: finding T12 by following the last rib, finding L4 from the level of the iliac crests and finding L5 by following the sacrum (Oliver and Middleditch, 1991).

The area to the left of each of the marked locations was cleaned with isopropyl alcohol and shaved if necessary, in preparation for the electrode attachment. The active bipolar electrodes (Biometrics SX-230, Biometrics Ltd., Gwent) were attached longitudinally to the skin overlying the belly of the left erector spinae, $3.5 \mathrm{~cm}$ laterally of the midline next to the marked levels (Stokes et al., 2003; Wolf et al., 1991). The ground-reference electrode was placed around the subject's left hand. Since the sEMG amplitude is not significantly different between left and right sides on healthy individuals (Lariviere et al., 2000; Mannion et al., 1997) and because the vertebrae move mainly in the sagittal plane during central posteroanterior mobilisation (Lee and Evans, 1997; Powers et al., 2003), it was not deemed necessary to apply electrodes bilaterally.

Electrodes were placed at L5, L3 and T10 to sample sEMG of erector spinae. Altered muscle activity was expected to occur at 
these locations since a central PA on L3 produces movement between T7 and the sacrum (Lee and Svensson, 1993). The electrodes' positions were not changed until their removal at the end of the experiment. To standardise subject position, the head was in neutral using the plinth face hole and with the arms by their side.

Surface EMG measurements were amplitude normalised to a standardised activity designed to elicit a stable submaximal voluntary contraction (O'Sullivan et al., 2002). This was performed because normalisation to a maximal voluntary contraction has poor reliability (McGill, 1991), and reduces the ability to detect small changes in levels of motor activity during quiet standing (Snijders et al., 1995). The normalisation activity was prone-lying bilateral active knee flexion, in which the heels were raised $20 \mathrm{~cm}$ and held for $5 \mathrm{~s}$ (O'Sullivan et al., 2002) (Fig. 1). During this period, the activity of the erector spinae at the three levels was recorded. The active bipolar electrodes (Biometrics SX-230, Biometrics Ltd., Gwent) were attached longitudinally to the skin overlying the belly of the left erector spinae, $3.5 \mathrm{~cm}$ laterally of the midline next to the marked levels (Stokes et al., 2003; Wolf et al., 1991). Electrodes were of integral dry reusable type. The gain was set at 1000, the bandwidth was $20-450 \mathrm{~Hz}$, noise was below $5 \mathrm{lV}$, input impedance was more than $10,000,000 \mathrm{MX}$. The supply voltage was $+4.5 \mathrm{Vdc}, \mathrm{CMRR}$ at $60 \mathrm{~Hz}(\mathrm{~dB})$ was higher than $96 \mathrm{~dB}$ (typically $110 \mathrm{~dB}$ ), channel sensitivity was $3 \mathrm{~V}$, the sampling rate was $1 \mathrm{kHz}$ and the excitation output $4950 \mathrm{mV}$. To standardise the height of the heel-raise, a wooden height-adjustable board was used to block the subject's feet. The distance between the heels and the board was individually adjusted for each subject to ensure consistency. After the 5-s recording, the subject lowered their heels and stood up.

To standardise the standing posture, the participants were barefoot with arms relaxed and lightly clasped in front of their body and feet positioned $20 \mathrm{~cm}$ apart (O'Sullivan et al., 2002). To help with the feet positioning, there was a rectangular border on the floor made of coloured adhesive tape $20 \mathrm{~cm}$ wide. The subject was asked to stand still for $5 \mathrm{~s}$ during which the resting activity of the erector spinae at the three levels was again recorded. The above sequence was repeated for each subject in the same order.

Different methods have been utilised in the analysis of EMG signals, including rectification, averaging or integration of rectified signals and the derivation of root mean square (RMS) values (DeLuca, 1997; Ferdjallah and Wertsch, 1998; Kollmitzer et al., 1999; McGill et al., 1996; Ng and Richardson, 1994). According

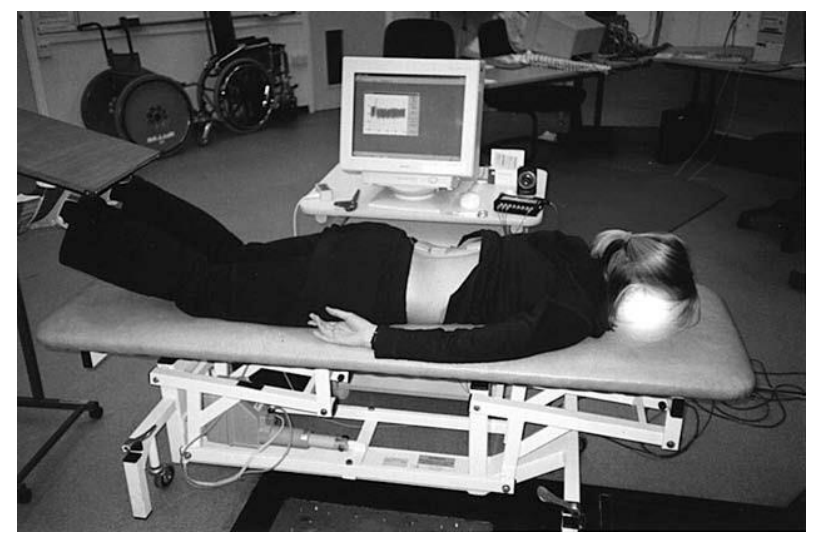

Fig. 1. Normalisation procedure. The subject lay prone with both knees flexed and pushed their heels (active knee flexion) against a fixed board for $5 \mathrm{~s}$; sEMG recordings were taken at the three spinal levels during this time period. to DeLuca (1997), the RMS values are more appropriate measurements of signal amplitude, represent the signal power, and therefore have a clear physical meaning. In addition, there may be a linear relationship between RMS EMG and torque of erector spinae at different exertion levels during trunk extension in the standing position (Tan et al., 1993). Consequently, RMS EMG was the method of data analysis employed in this study.

In total, five sets of raw SEMG data were recorded from each subject. A waveform editing software (Biometrics Datalink) was used to identify and isolate the third second of the 5-s raw EMG data recorded in the testing procedure (Ng and Richardson, 1994; Sterling et al., 2001). After that $1 \mathrm{~s}$ was extracted, the above software was utilised to convert the raw signal to RMS data. The maximum RMS EMG values were used for subsequent analysis (Ng and Richardson, 1994; Sterling et al., 2001).

To enable comparison between the conditions (EMG before and EMG after each of the three experimental conditions), the RMS EMG data were expressed as a percentage of that recorded during the normalisation task. The derived percentages were used to detect any changes in EMG activity between the stages of the experiment using the appropriate statistical tests.

\subsection{Experimental conditions}

Following the above, three experimental conditions were randomly applied to each subject, control (C), placebo (P) and posteroanterior (PA) mobilisation. The conditions were administered within the same session for each participant. After each condition, the subject assumed the same erect posture described earlier and the sEMG activity was re-measured again for $5 \mathrm{~s}$.

The three experimental conditions were:

1. Control: No physical contact between the subject and the researcher (GK). The participant lay on the plinth for $2 \mathrm{~min}$.

2. Placebo: In prone lie, the researcher placed his right middle finger on the L3 spinous process for $2 \mathrm{~min}$.

3. Mobilisation: In prone lie, the researcher stood on a force platform (Kistler, Winterthure) and applied a central posteroanterior mobilisation using the pisiform grip (Maitland et al., 2005) with an oscillating force from $60 \mathrm{~N}$ to $100 \mathrm{~N}$ force, a frequency of $1.2 \mathrm{~Hz}$ for $2 \mathrm{~min}$. The sampling frequency for the force platform was set at $10 \mathrm{~Hz}$, with a measuring range from 0 to $180 \mathrm{~N}$. The application of $100 \mathrm{~N}$ force has been shown to produce spinal movement (Keller et al., 2002; Lee and Svensson, 1993; Lee and Evans, 1992). The forces applied by the therapist is estimated from the difference between the vertical ground-reaction force and the researcher's body mass, providing an indirect measure of maximum applied force, minimum applied force and frequency of oscillation. The force platform has been found to be a valid instrument to quantify these measures during central posteroanterior mobilisation (Petty and Messenger, 1996) and a visual display in real time guided the researcher to apply the required oscillatory force. The sampling frequency for the force platform was set at $10 \mathrm{~Hz}$, with a measuring range from $0 \mathrm{~N}$ to $180 \mathrm{~N}$. A computer connected to the force platform and Kistler bioware software calculated the mean minimum and mean maximum forces for each subject. A metronome was set to 72 beats per minute that corresponded to $1.2 \mathrm{~Hz}$ and guided the speed of oscillation. The period of $2 \mathrm{~min}$ and the frequency of oscillation were considered to be in accordance with current practice. 


\section{Data management}

The software package (Bioware) managing the Kistler platform (Kistler, Winterthure) was used to calculate, record and store the force data. The SPSS (version 14) statistical software package was used for all analyses. Descriptive statistics (mean, standard deviation and range) were calculated for the normalised RMS SEMG values at L3, L5 and L10 for males and females under each experimental condition. The mean of the normalised RMS sEMG values at L3, L5 and T10 was calculated for each subject and logarithmically transformed to achieve approximate normality prior to further analysis. Differences between the experimental conditions and males and females were investigated using repeated measures analysis of variance with the Huynh-Feldt adjustment. Post hoc multiple comparisons with Bonferroni adjustments were used for pairwise comparisons between conditions. The level of significance chosen for this analysis was $p<0.05$.

\section{Results}

The individual characteristics (age, height, mass, BMI) of the participants are summarised in Table 1.

The mean maximum force applied, overall for 36 participants, during the PA mobilisation was $103.3 \mathrm{~N}$ (range 96$110.2 \mathrm{~N}, \mathrm{SD} 3.9 \mathrm{~N}$ ) and the mean minimum force applied was 62.2 N (range 54.9-69.2 N, SD $3.2 \mathrm{~N}$ ) (Fig. 2). The mean amplitude of force oscillation was $41.1 \mathrm{~N}$ (range 32.3-55.6 N, SD 4.96 N).

The descriptive statistics for the normalised RMS sEMG values at L3, L5 and L10 for males and females under each experimental condition are given in Table 2 .

The repeated measures analysis of variance indicated that there were significant differences between the experimental conditions $(p<0.001)$ but not between males and females $(p=0.156)$. The interaction between experimental condition and gender was also not significant $(p=0.215)$ indicating there was no statistical evidence that gender affected the difference in response to the experimental conditions. Pairwise comparisons between the experimental conditions showed that the mobilisation mean SEMG was significantly lower than either the control or the placebo means $(p<0.001)$, and that there was no significant difference between the control and the placebo means. The estimated mean reductions in SEMG value following mobilisation compared with the control and placebo, respectively, were $15.5 \%$ (95\% CI: $8.0-22.5 \%$ ) and $17.8 \%$ (95\% CI: $12.9-22.4 \%)$.

Table 1

Demographic characteristics of participants $(N=36)$

\begin{tabular}{lllcc}
\hline & Minimum & Maximum & Mean & SD \\
\hline Age (years) & 18 & 48 & 26.8 & 7.1 \\
Height $(\mathrm{m})$ & 1.6 & 1.9 & 1.7 & 0.07 \\
Mass $(\mathrm{kg})$ & 51 & 97.5 & 67.1 & 11.4 \\
BMI $\left(\mathrm{kg} / \mathrm{m}^{2}\right)$ & 18.9 & 27.8 & 22.5 & 2.1 \\
\hline
\end{tabular}

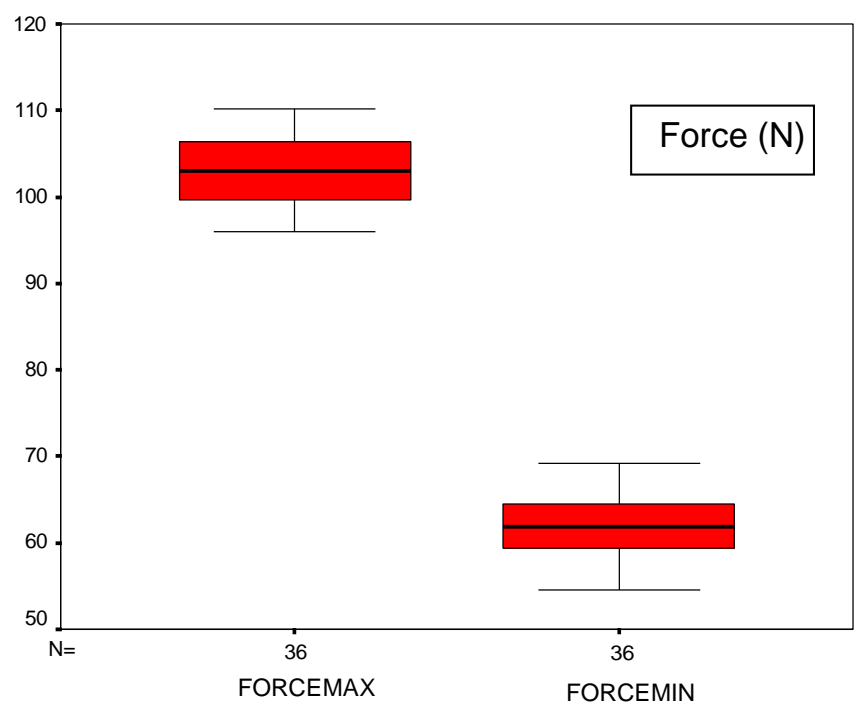

Fig. 2. Central PA mobilization to L3 for all subjects: mean maximum and mean minimum forces in Newtons (thick horizontal line), \pm 1 SD (shaded rectangle) with upper and lower limits.

\section{Discussion}

The aim of this study was to determine the effect of lumbar PA mobilisation on paraspinal sEMG of asymptomatic subjects. This study found that a central PA mobilisation (with a maximum force of $103.3 \mathrm{~N}$, and an amplitude of oscillation of $41.1 \mathrm{~N}$ ) on L3 with a frequency of $1.2 \mathrm{~Hz}$ for $2 \mathrm{~min}$ resulted in a statistically significant reduction $(p<0.05)$ in the average sEMG activity of the erector spinae musculature at L5, L3 and T10 levels compared with the placebo treatment and the control treatment.

In some respects these findings are consistent with previous studies. A decrease in resting SEMG of masseter was found following mandibular distraction mobilisation (Taylor et al., 1994). The only previous study assessing the effects of spinal mobilisation on SEMG activity was by Sterling et al. (2001). A decrease in sEMG of the neck flexors was found to occur following a unilateral PA mobilisation at $\mathrm{C} 5 / 6$ for $3 \mathrm{~min}$.

PA mobilisation forces at L3 with a magnitude of $100 \mathrm{~N}$, as used in this study, has been found to cause segmental movement of the lumbar spine and generalised extension of the spine as far as T7 (Keller et al., 2002; Lee et al., 1993; Lee and Evans, 1992, 1997; Lee and Svensson, 1993; Powers et al., 2003). It has been proposed that end-range lumbar PA mobilisation may reduce paraspinal muscle activity (Zusman, 1986), however the position of 'end range' is ambiguous. It is not known whether the $100 \mathrm{~N}$ as used in this study is sufficient force to reach end range and in addition it is known that therapists use much higher forces in clinical practice, up to $350 \mathrm{~N}$ (Harms and Bader, 1997). It is possible that if higher forces had been used in this study, a greater difference in SEMG may have been found between the mobilisation group compared to the placebo and control group. 
Table 2

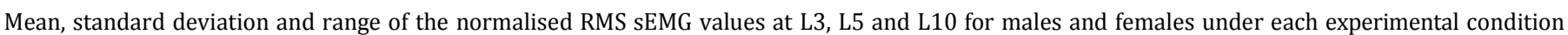

\begin{tabular}{|c|c|c|c|c|}
\hline & & Control & Placebo & Mobilisation \\
\hline \multirow[t]{2}{*}{ L3 } & Male $(n=10)$ & $68.0,39.5$ (16.9-139.5) & $75.6,59.5$ (20.3-214.6) & $66.9,63.7$ (15.3-221.9) \\
\hline & Female $(n=26)$ & $82.0,44.8(17.0-182.0)$ & $81.8,44.1(15.8-174.5)$ & $66.2,40.7(10.3-174.3)$ \\
\hline \multirow[t]{2}{*}{ L5 } & Male $(n=10)$ & $49.2,29.9$ (11.9-104.6) & 50.3, 30.7 (14.5-103.9) & $38.6,20.2(11.5-76.6)$ \\
\hline & Female $(n=26)$ & $112.3,115.0(26.1-484.3)$ & $110.4,109.6(29.1-425.4)$ & $91.7,94.0(22-366.7)$ \\
\hline \multirow[t]{2}{*}{$\mathrm{T} 10$} & Male $(n=10)$ & 83.8, $71.1(11.3-267.2)$ & $86.2,49.6(38.5-205.4)$ & $73.9,51.0(11-195.4)$ \\
\hline & Female $(n=26)$ & $101.0,67.2(28.2-336.0)$ & $102.3,68.1(33.2-332.8)$ & $88.8,66.5(27.9-326.1)$ \\
\hline \multirow[t]{2}{*}{ Average at L3, L5 and T10 } & Male $(n=10)$ & $67.0,35.8(13.3-144.1)$ & $70.7,31.0(24.7-114.6)$ & $59.8,32.5$ (18.7-116.9) \\
\hline & Female $(n=26)$ & $98.4,61.6(30.8-262.4)$ & $98.1,59.0(31.6-231.9)$ & $82.3,52.2(22.6-204.2)$ \\
\hline
\end{tabular}

The PA mobilisation and the placebo treatment involved force applied to L3. Following mobilisation the greatest decrease in median sEMG activity relative to the control was at L3 then L5 then T10 (Table 2). This suggests that the effect of PA mobilisation may be greatestnearest to where the force is applied. The reason for this difference is unclear, but is consistent with the effects of PA mobilisation on spinal movement, where greatest movement occurs at the mobilised level (Lee and Evans, 1997; Lee and Svensson, 1993).

A variety of mechanisms have been proposed to explain the reduction in muscle activity and the subsequent therapeutic effect of passive joint movement (Zusman, 1986). Physiological studies on animals have demonstrated that joint afferent activity causes a reduction in muscle excitability (Baxendale and Ferrell, 1981; Lundberg et al., 1978). End-range passive movements have been found to have a hypoalgesic effect (Sluka et al., 2006; Vicenzino et al., 1996, 1998; Wright and Vicenzino, 1995) and this may then cause a reduction in muscle activity. Passive movements may increase muscle spindle activity (Bolton and Budgell, 2006; Cheng et al., 1995; Dishman and Burke, 2003; Lewis et al., 2001), and at end range stimulate golgi tendon organ activity (Lundberg et al., 1978), lea ding to a reflex inhibition of muscle. A reduction in muscle activity following mobilisation may reduce muscle tension on periarticular tissues leading to reduced joint afferent activity (Grigg, 1976; Millar, 1973; Zusman, 1986) and relief of pain. It is unclear from this present study, what underlying mechanisms produced the reduction in sEMG activity, although hypoalgesic effects seem less likely as the subjects were asymptomatic.

There are some limitations to this study. Surface electromyography is not able to select particular muscles due to cross-talk (Basmajian and DeLuca, 1985; Dimitru et al., 2001; Farina and Rainoldi, 1999; Sabatino et al., 1992; Solomonow et al., 1994; van Vugt and van Dijk, 2000; Wolf et al., 1991) and so it may be that the data obtained in this study includes activity from other local muscles than erector spinae. In addition, the subjects were young and asymptomatic and differing results might well have been obtained from older and symptomatic people.

\section{Conclusion}

This study found that a central PA mobilisation (with a maximum force of $103.3 \mathrm{~N}$, and an amplitude of oscillation of $41.1 \mathrm{~N}$ ) on L3 with a frequency of $1.2 \mathrm{~Hz}$ for $2 \mathrm{~min}$ resulted in a statistically significant reduction $(p<0.05)$ in the average sEMG activity of the erector spinae musculature at L5, L3 and T10 levels compared with the placebo treatment and the control treatment. 


\section{References}

Baxendale RH, Ferrell WR. The effect of knee joint afferent discharge on transmission in flexion reflex pathways in decerebrate cats. J Physiol 1981;315:231-42.

Basmajian JV, DeLuca CJ. Muscles alive: their functions revealed by electromyography. 5th ed. Baltimore: Williams and Wilkins; 1985.

Binkley J, Stratford PW, Gill C. Interrater reliability of lumbar accessory motion mobility testing. Phys Therapy 1995;75(9):786-95.

Bolton PS, Budgell BS. Spinal manipulation and spinal mobilization influence different axial sensory beds. Med Hypotheses 2006;66: 258-62.

Chen W-J, Chiou W-K, Lee Y-H, Lee M-Y, Chen M-L. Myo-electric behaviour of the trunk muscles during static load holding in healthy subjects and low-back pain patients. Clin Biomech 1998;13(Suppl. 1): S9-S15.

Cheng J, Brooke JD, Misiaszek JE, Staines WR. The relationship between the kinematics of passive movement, the stretch of extensor muscles of the leg and the change induced in the gain of the soleus $\mathrm{H}$ reflex in humans. Brain Res 1995;672(1-2):89-96.

Chiou W-K, Lee W-H, Chen W-J. Use of surface EMG coactivational pattern for functional evaluation of trunk muscles in subjects with and without low-back pain. Int J Ind Ergonom 1999;23:51-60.

Colloca CJ, Keller TS. Stiffness and neuromuscular reflex response of the human spine to posteroanterior manipulative thrusts in patients with low back pain. J Manipulat Physiol Ther 2001;24(8):489-500.

DeLuca CJ. The use of surface electromyography in biomechanics. J Appl Biomech 1997;13:135-63.

DeVocht JW, Pickar JG, Wilder DG. Spinal manipulation alters electromyographic activity of paraspinal muscles: a descriptive study. J Manipulat Physiol Ther 2005;28:465-71.

Dimitru D, Amato A, Zwarts M. Electrodiagnostic medicine. 2nd ed. Philadelphia: Hanley and Belfus; 2001.

Dishman JD, Burke J. Spinal reflex excitability changes after cervical and lumbar spinal manipulation: a comparative study. Spine J 2003;3: 204-12.

Edwards DJ, Thickbroom GW, Brynes ML, Ghosh S, Mastaglia FL. Reduced corticomotor excitability with cyclic passive movement: a study using transcranial magnetic stimulation. Human MovementSci 2002;21:533-40.

Farina D, Rainoldi A. Compensation of the effect of sub-cutaneous tissue layers on surface EMG: a simulation study. Med Eng Phys 1999;21: 487-96.

Ferdjallah M, Wertsch J. Anatomical and technical considerations in surface electromyography. Phys Med Rehab Clin North America 1998;9(4):925-31.

Freeman MAR, Wyke B. Articular reflexes at the ankle joint: an electromyographic study of normal and abnormal influences of ankle-joint mechanoreceptors upon reflex activity in the leg muscles. BrJSurg 1967;54(12):990-1001.

Grigg P. Response of joint afferent neurons in cat medial articular nerve to active and passive movements of the knee. Brain Res 1976;18:482-5.

Harms M, Bader D. Variability of forces applied by experienced therapists during spinal mobilization. Clin Biomech 1997;12(6):393-9.

Hicks C. Research for physiotherapists. Project design and analysis. 2nd ed. Edinburgh: Churchill Livingstone; 1995.

Hodges P, Bui BH. A comparison of computer based methods for the determination of onset of muscle contraction using electromyography. Electroencephalogr Clin Neurophysiol 1996;101:511-9.

Jenkins S, Price CJ, Straker L. The researching therapist. A practical guide to planning, performing and communicating research. Edinburgh: Churchill Livingstone; 1998.

Keller TS, Colloca CJ, Beliveau J-G. Force deformation response of the lumbar spine: a sagittal plane model of posteroanterior manipulation and mobilisation. Clin Biomech 2002;17:185-96.

Kollmitzer J, Ebenbichler GR, Kopf A. Reliability of surface electromyographic measurements. Clin Neurophysiol 1999;110(4):725-34.
Lariviere C, Gagnon D, Loisel P. The comparison of trunk muscles EMG activation between subjects with and without chronic low back pain during flexion-extension and lateral bending tasks. J Electromyogr Kinesiol 2000;10:79-91.

Latimer J, Lee M, Adams R, Moran C. An investigation of the relationship between lumbar posteroanterior mobility and low back pain. J Manipulat Physiol Ther 1996;19(9):587-91.

Lee M, Svensson NL. Effect of frequency on response of the spine to lumbar posteroanterior forces. J Manipulat Physiol Ther 1993;16: 439-46.

Lee M, Moseley A, Refshauge KM. Effect of feedback on learning a vertebral joint mobilization skill. Phys Therapy 1990;90(2):97-102.

Lee M, Esler M-A, Mildren J, Herbert R. Effect of extensor muscle activation on the response to lumbar posteroanterior forces. Clin Biomech 1993;8:115-9.

Lee M, Lau H, Lau T. Sagittal plane rotation of the pelvis during lumbar posteroanterior loading. J Manipulat Physiol Ther 1994;17(3): 149-55.

Lee R, Evans J. Load-displacement-time characteristics of the spine under posteroanterior mobilisation. Aust J Physiother 1992;38(3): 115-9.

Lee R, Evans J. An in vivo study of the interverteral movements produced by posteroanterior mobilisation. Clin Biomech 1997;12(6):400-8.

Lehman G. Clinical consideration in the use of surface electromyography: three experimental studies. J Manipulat Physiol Ther 2002;25(5):293-9.

Lewis GN, Byblow WD, Carson RG. Phasic modulation of corticomotor excitability during passive movement of the upper limb: effects of movement frequency and muscle specificity. Brain Res 2001;900: 282-94.

Lofland K, Cassisi J, Levin J, Palumbo N, Blonsky E. The incremental validity of lumbar surface EMG, behavioral observation, and a symptom checklist in the assessment of patients with chronic low-back pain. Appl Psychophysiol Biofeedback 2000;25(2):67-78.

Lundberg A, Malmgren K, Schomburg ED. Role of joint afferents in motor control exemplified by effects on reflex pathways from Ib afferents. J Physiol 1978;284:327-43.

Maitland G, Hengeveld E, Banks K, English K. Maitland's vertebral manipulation. 6th ed. Oxford: Butterworth-Heinemann; 2005.

Mannion AF, Connolly B, Wood K, Dolan P. The use of surface EMG power spectral analysis in the evaluation of back muscle function. J Rehab Res Dev 1997;34(4):427-39.

McGill S. Electromyographic activity of the abdominal and low-back musculature during the generation of isometric and dynamic axial trunk torque: implications for lumbar mechanics. J Orthopaedic Res 1991;9:91-103.

McGill S, Juker D, Kropf P. Appropriately placed surface EMG electrodes reflect deep muscle activity in the lumbar spine. J Biomech 1996;29(11):1503-7.

McKenzie A, Taylor N. Can physiotherapists locate lumbar spinal levels by palpation?. Physiotherapy 1997;8(5):235-9.

Millar J. Joint afferent fibres responding to muscle stretch, vibration and contraction. Brain Res 1973;63:380-3.

Newton M, Waddell G. Reliability and validity of clinical measurement of the lumbar spine in patients with chronic low back pain. Physiotherapy 1991;77(12):796-800.

$\mathrm{Ng} \mathrm{JK}$, Richardson C. EMG study of erector spinae and multifidus in two isometric back extension exercises. Aust J Physiother 1994;40(2): 115-21.

Oliver MJ, Middleditch A. Functional anatomy of the spine. London: Butterworth-Heinemann; 1991.

O'Sullivan P, Grahamslaw K, Kendell M, Lapenskie S, Moller N, Richards K. The effect of different standing and sitting postures on trunk muscle activity in a pain-free population. Spine $2002 ; 27(11)$ 1238-44.

Petty NJ, Messenger N. Can the force platform be used to measure the forces applied during a PA mobilisation of the lumbar spine?. J Manual Manipulat Ther 1996;4(2):70-6. 
Powers C, Kulig K, Harrison J, Bergman G. Segmental mobility of the lumbar spine during a posterior to anterior mobilization: assessment using dynamic MRI. Clin Biomech 2003;18:80-3.

Ritvanen T, Zaproudina N, Nissen M, Leinonen V, Hanninen 0. Dynamic surface electromyographic responses in chronic low back pain treated by traditional bone setting and conventional physical therapy. J Manipulat Physiol Ther 2007;30:31-7.

Sabatino M, Ferraro G, Caravaglios G, Sardo P, Delwaide PJ, La Grutta $\mathrm{V}$. Evidence of a contralateral motor influence on reciprocal inhibition in man. J Neural Trans Parkinson's Dis Dementia Sect 1992;4:257-66.

Shirley D. Manual therapy and tissue stiffness. In: Boyling JD, Jull GA, editors. 3rd ed. Grieve's modern manual therapy, the vertebral column. Edinburgh: Churchill Livingstone; 2004. p. 381-90.

Shirley D, Lee M, Ellis E. The relationship between submaximal activity of the lumbar extensor muscles and lumbar posteroanterior stiffness. Phys Therapy 1999;79(3):278-85.

Sluka KA, Skyba DA, Radhakrishnan R, Leeper BJ, Wright A. Joint mobilization reduces hyperalgesia associated with chronic muscle and joint inflammation in rats. J Pain 2006;7(8):602-7.

Snijders CJ, Slagter AH, van Strik R, Vleeming A, Stoeckart R, Stam HJ. Why leg crossing? The influence of common postures on abdominal muscle activity. Spine 1995;20(18):1989-93.

Solomonow M, Baratta RV, Bernardi M, Zhou B, Lu Y, Acierno S. Surface and wire EMG crosstalk in neighbouring muscles. J Electromyogr Kinesiol 1994;4:131-42.

Sterling M, Jull G, Wright A. Cervical mobilisation: concurrent effects on pain, sympathetic nervous system activity and motor activity. Manual Ther 2001;6(2):72-81.

Stokes IA, Henry SM, Single RM. Surface EMG electrodes do not accurately record from lumbar multifidus muscles. Clin Biomech 2003;18(1):9-13.

Tan JC, Parnianpour M, Nordin M, Hofer H, Willems B. Isometric maximal and submaximal trunk extension at different flexed positions in standing. Triaxial torque output and EMG. Spine 1993;18(16): 2480-90.

Taylor M, Suvinen T, Reade P. The effect of grade IV distraction mobilisation on patients with temporomandibular pain-dysfunction disorder. Physiother Theory Practice 1994;10:129-36.

van Vugt JPP, van Dijk JG. A convenient method to reduce crosstalk in surface EMG. Clin Neurophysiol 2000;112:583-92.

Vicenzino B, Collins D, Wright A. The initial effects of a cervical spine manipulative physiotherapy treatment on the pain and dysfunction of lateral epicondylalgia. Pain 1996;68:69-74.

Vicenzino B, Collins D, Benson H, Wright A. An investigation of the interrelationship between manipulative therapy-induced hypoalgesia and sympathoexcitation. J Manipulat Physiol Ther 1998;21(7):448-53.

Wolf L, Segal R, Wolf S, Nyberg R. Quantitative analysis of surface and percutaneous electromyographic activity in lumbar erector spinae of normal young women. Spine 1991;16(2):155-61.
Wright A, Vicenzino B. Cervical mobilization techniques, sympathetic nervous system effects and their relationship to analgesia. In: Shacklock MO, editor. Moving in on pain. Australia: Butterworth-Heinemann; 1995. p. 164-73.

Zusman M. Spinal manipulative therapy: review of some proposed mechanisms and a new hypothesis. Aust J Physiother 1986;32(2):89-99. 